\title{
A New Cryogenic Air Separation Process with Flash Separator
}

\author{
Zeinab A. M. Khalel, Ali A. Rabah, and Taj Alasfia M. Barakat \\ Department of Chemical Engineering, Faculty of Engineering, University of Khartoum, P.O. Box 321, Khartoum 11111, Sudan \\ Correspondence should be addressed to Ali A. Rabah; rabahss@hotmail.com
}

Received 15 May 2013; Accepted 13 June 2013

Academic Editors: R. R. Burnette, T. Chen, P. Espeau, and P. Trens

Copyright (C) 2013 Zeinab A. M. Khalel et al. This is an open access article distributed under the Creative Commons Attribution License, which permits unrestricted use, distribution, and reproduction in any medium, provided the original work is properly cited.

A new cryogenic air separation process with flash separator is developed. A flash separator is added to the conventional doublecolumn cryogenic air separation process. The flash separator is used to replace the turbine required to recover a portion of the energy in the double-column air separation process. The flash separator served dual purposes of throttling and separation. Both the conventional and the new processes are simulated using Aspen Plus version 11.1 the model air flow rate and compositions are taken as $50000 \mathrm{Nm}^{3} / \mathrm{h}$ of air at standard conditions of 1 atm and $25^{\circ} \mathrm{C}$ and feed composition of $79.1 \% \mathrm{~N}_{2}$ and $20.9 \% \mathrm{O}_{2}$. The new process decreases the energy consumption and increases the productivity.

\section{Introduction}

There are mainly three methods of air separation, cryogenic distillation, pressure swing absorption, and membrane separation. Although the latter two methods have become more competitive, cryogenic distillation remained the dominant choice for mass production of high-purity $\mathrm{O}_{2}$. The first cryogenic distillation unit with single-column was built in 1902 and shortly followed by double-column process. The double column consists of compressors, low- and highpressure columns, and two sets of heat exchangers. The lowand high-pressure columns are thermally interconnected [1].

Although the double-column process is widely used, its high energy consumption remains challenging. Therefore in the recent past, the double column has been subjected to many energy-efficient modifications such as changing the operation condition of the low-pressure column from low to moderate pressure [2]. This modification resulted in smaller size of the column and 10\% energy savings. The modification has also the advantage of argon recovery (up to 5\% greater argon recovery over the conventional). Another modification is the addition of a heat pump to a side rectifier which is thermally linked to the two columns. The heat pump enhances the separation by providing a supplementary crude argon condensing duty [3]. Reference [4] did an exergy analysis of the double-column air separation process. It found that more than half of the exergy loss takes place in the liquefaction unit and almost one-third in the air compression unit, and minor exergy losses are taking place in the distillation unit and the main heat exchangers. Reference [5] has changed the design of the double column to single column using self-heat recuperation technology (i.e., heat from the top vapor stream is recuperated and exchanged with heat in the bottom liquid and feed streams). The author's modifications have improved the energy consumption by around $36 \%$ of the conventional process.

This work is aimed to develop an energy-efficient air separation process. Flash separator has the advantage of working as throttling device on one hand and vapor liquid separation unit on the other hand. It is introduced into the conventional double-column air separation process to replace the turbine needed to expand the air prior to injection to lower-pressure distillation column.

\section{Process Description}

Figure 1 shows schematic presentation of the conventional double-column cryogenic air separation process. It consists of two compressors ( $\mathrm{C} 1$ and $\mathrm{C} 2$ ), a turbine ( $\mathrm{T}$ ), two thermally linked distillation columns (low-pressure column (LPC) and high-pressure column (HPC)), and two sets of heat exchangers (HX1, HX2). The air is compressed from atmospheric pressure to $6 \mathrm{~atm}$ in $\mathrm{C}$. The compressed air is then split into 


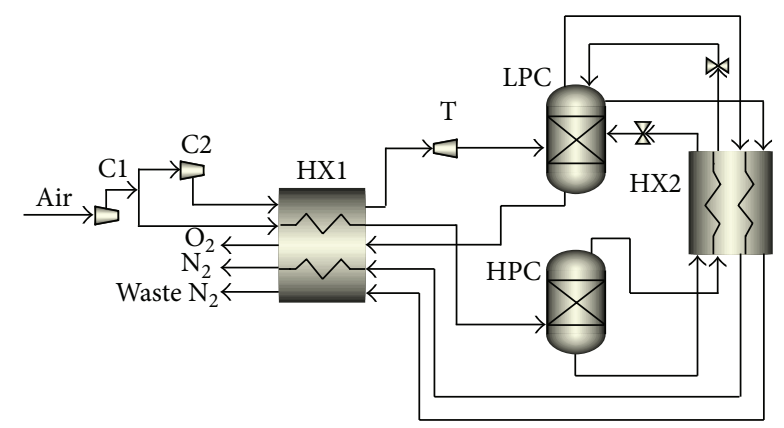

FIgURE 1: Conventional double-column cryogenic air separation process.

two streams; one stream for HPC (hereafter is called HPC split) and the other stream for LPC (hereafter is called LPC split). The LPC split is compressed in C2 further to $7.5 \mathrm{~atm}$, cooled in $\mathrm{HXl}$, throttled in $\mathrm{T}$ to $1.3 \mathrm{~atm}$, and finally fed to LPC. The HPC split is cooled in HX1 and then fed to HPC. The products of LPC are pure $\mathrm{N}_{2}$ (top), pure $\mathrm{O}_{2}$ (bottom), and waste $\mathrm{N}_{2}$ (side stream). The products of HPC are pure $\mathrm{N}_{2}$ (top) and air-enriched oxygen (bottom). The pure $\mathrm{N}_{2}$ of HPC is working as reflux to the LPC and the air-enriched oxygen of HPC is an extra feed to the LPC. The two columns are thus thermally linked by exchanging the latent heat of vaporization via condenser of the HPC and reboiler of the LPC. The products of the LPC are liquid pure oxygen from the bottom, gas pure nitrogen from the top, and side product of waste nitrogen; all these products are heated in the two sets of heat exchangers prior to be sent as final products.

Figure 2 shows schematic presentation of the new cryogenic air separation process with flash separator. The air is compressed in C3 from atmospheric pressure to $4 \mathrm{~atm}$ instead of $6 \mathrm{~atm}$ as in the conventional process then split into two streams. The HPC split is compressed in C4 further to $6 \mathrm{~atm}$ and subsequently cooled in HX1 and then injected to HPC. Hence this stream is maintained at the same conditions as these in the conventional process. The LPC split is cooled in $\mathrm{HX} 1$ and then throttled in a flash separator (F) to $1.3 \mathrm{~atm}$. The bottom product of the flash separator is air-enriched $\mathrm{O}_{2}$ and the top product is a waste $\mathrm{N}_{2}$. The waste $\mathrm{N}_{2}$ is a final product (mixed with the waste nitrogen from the LPC). The bottom product of the flash (air-riched $\mathrm{O}_{2}$ ) is fed to the LPC. The rest of the process remains the same as in the conventional process.

Clearly the flash separator replaces the turbine of the conventional double column. Although the turbine is used to recover part of the work introduced into the compressors, the other point to be noticed in this new design is that the LPC split is compressed to $4 \mathrm{~atm}$ only rather than $7.5 \mathrm{~atm}$ as in the conventional process.

\section{Simulation}

Both the conventional and the new cryogenic air separation processes are simulated using Aspen Plus version 11.1 with the Peng-Robinson equation of state as a fluid package [6].
TABLE 1: Model air specification.

\begin{tabular}{lcc}
\hline Parameter & Value & Unit \\
\hline Flow rate & 50000 & $\mathrm{Nm}^{3} / \mathrm{h}$ \\
Pressure & 1 & $\mathrm{~atm}$ \\
Temperature & 298 & ${ }^{\circ} \mathrm{K}$ \\
$\mathrm{N}_{2}$ & 79.1 & Mole \% \\
$\mathrm{O}_{2}$ & 20.9 & Mole \% \\
\hline
\end{tabular}

TABLE 2: Design and operating conditions of distillation columns.

\begin{tabular}{lcc}
\hline Parameter & LPC & Column \\
& 20 & HPC \\
\hline No. of stages & $2141 \mathrm{~kW}$ & 15 \\
Reboiler duty & - & - \\
Condenser duty & & $2146 \mathrm{~kW}$ \\
\hline
\end{tabular}

The following assumptions are considered in this work.

(1) The model air is assumed to gain $5 \mathrm{~K}$ in the processes of drying and cleaning prior to the inlet of the main compressor.

(2) The pressure drop across the heat exchangers is taken as $0.1 \mathrm{~atm}$.

(3) The pressure drop along the HPC and the LPC is $0.1 \mathrm{~atm}$.

(4) The minimum temperature approach is $1.5 \mathrm{~K}$ for the $\mathrm{HX} 1$ and $2.5 \mathrm{~K}$ for $\mathrm{HX} 2$.

(5) $5 \mathrm{~kW}$ is lost during the thermal integration between the two columns.

The model air flow rate and composition are shown in Table 1.

The compressors $\mathrm{Cl}, \mathrm{C} 3$, and $\mathrm{C} 4$ are simulated as multistage compressors (two stages), while $\mathrm{C} 2$ is simulated as single stage because the pressure difference is only $1.5 \mathrm{~atm}$. The cooling duty for multistage compressor is neglected as cooling water is assumed to be taken from large reservoir like the electrical energy consumed in pumps. The pumps are considered as auxiliary devices and common in both conventional and new processes. The distillation columns in both processes are simulated by a block known as RadFrac. The two sets of heat exchangers (HX1, HX2) are simulated by block called MHeatX.

\section{Results and Discussion}

The core of any cryogenic air separation process is distillation unit; here and as mentioned before the HPC split specification remains the same in the conventional and new processes, so the value of the condenser duty of the HPC from the first run is input as the value of the reboiler duty of the LPC. These values are shown in Table 2. Also the number of stages of the HPC and the LPC is adjusted using the composition profile; the number of stages is taken when there is no much difference in the product purities with the increased number of states; the number of stages is given in Table 2. 
TABLE 3: Specification of product streams.

\begin{tabular}{|c|c|c|c|c|c|c|}
\hline \multirow{2}{*}{ Product } & \multicolumn{3}{|c|}{ Conventional process } & \multicolumn{3}{|c|}{ New process } \\
\hline & Flow rate & $\mathrm{O}_{2}$ & $\mathrm{~N}_{2}$ & Flow rate & $\mathrm{O}_{2}$ & $\mathrm{~N}_{2}$ \\
\hline $\mathrm{O}_{2}(\mathrm{~g})$ & 8038 & 99.99 & 0.01 & 9189 & 99.98 & 0.02 \\
\hline $\mathrm{N}_{2}(\mathrm{~g})$ & 10602 & 0.13 & 99.87 & 11178 & 0.13 & 99.87 \\
\hline Waste $\mathrm{N}_{2}(\mathrm{~g})$ & 31360 & 7.65 & 92.35 & 29633 & 4.21 & 95.79 \\
\hline
\end{tabular}

TABLE 4: Specification of energy consumption units.

\begin{tabular}{|c|c|c|c|c|c|c|}
\hline \multirow{3}{*}{ Block } & \multicolumn{3}{|c|}{ Conventional process } & \multicolumn{3}{|c|}{ New process } \\
\hline & \multicolumn{2}{|c|}{ Pressure (atm) } & \multirow{2}{*}{ Work $(\mathrm{kW})$} & \multicolumn{2}{|c|}{ Pressure (atm) } & \multirow{2}{*}{ Work (kW) } \\
\hline & In & Out & & In & Out & \\
\hline $\mathrm{Cl}$ & 1 & 6 & 4390 & - & - & - \\
\hline $\mathrm{C} 2$ & 6 & 7.5 & 79 & - & - & - \\
\hline $\mathrm{C} 3$ & - & - & - & 1 & 4 & 3296 \\
\hline $\mathrm{C} 4$ & - & - & - & 4 & 6 & 748 \\
\hline Turbine/flash & 7.4 & 1.3 & -81 & 3.9 & 1.3 & - \\
\hline Net energy consumption & & & $4388 \mathrm{~kW}$ & & & $4044 \mathrm{~kW}$ \\
\hline Specific energy consumption & & & $0.55 \mathrm{~kW} \cdot \mathrm{h} / \mathrm{Nm}^{3} \mathrm{O}_{2}$ & & & $0.44 \mathrm{~kW} \cdot \mathrm{h} / \mathrm{Nm}^{3} \mathrm{O}_{2}$ \\
\hline
\end{tabular}

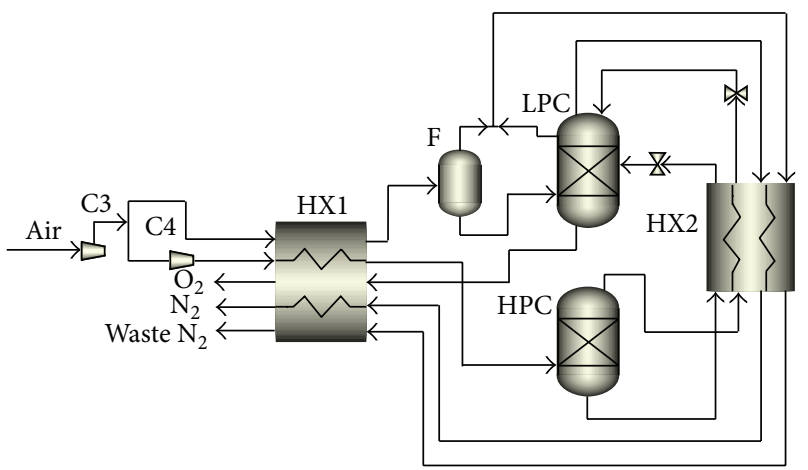

FIGURE 2: New cryogenic air separation process with flash separator.

Table 3 shows the simulation result of products flow rates and composition. It can be seen that there is no significant difference in the product purity of both process, but in the new process there is an increase in the flow rate of oxygen by $14.3 \%$ and nitrogen by $5.4 \%$, while the flow rate of the waste nitrogen (undesirable product) decreased by $5.5 \%$.

This is attributed to the change in LPC feed. In the new process the feed to LPC is reduced by the early separation of the waste $\mathrm{N}_{2}$ in the flash separator. Hence the feed is less in quantity and enrich in $\mathrm{O}_{2}$ than that in the conventional process. This change in the feed quantity and composition is expected to have either influence on the LPC unit specification or the quality of the product. Since the LPC column specifications are maintained similar to those in the conventional process, the feed change is reflected in the products quantity.

Also it is important to mention that in the conventional process the outlet pressure of $\mathrm{C} 2$ controlled the pressure drop

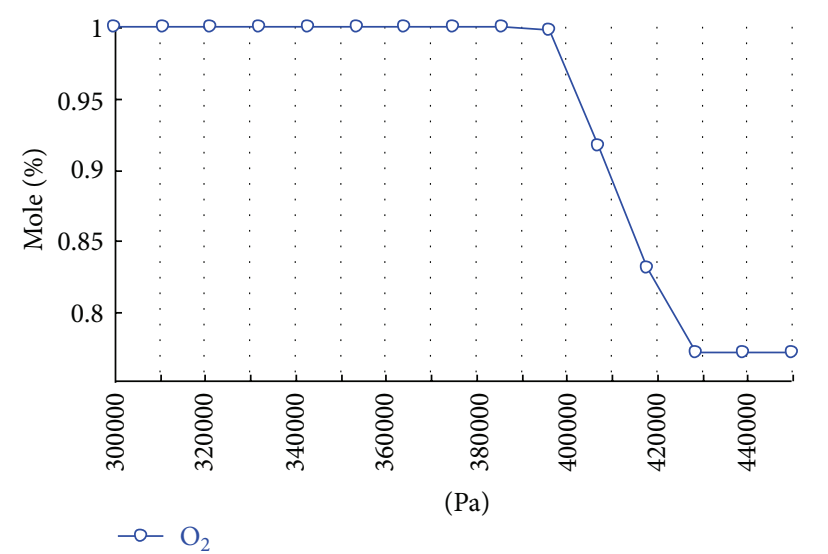

FIGURE 3: The outlet pressure of $\mathrm{C} 3$ versus product oxygen purity.

across the turbine and then the temperature drop across it, and it also affects the amount of recovered energy; on the other hand the outlet pressure of $\mathrm{C} 3$ in the new process manipulates the liquid fraction of air to the flash separator and, subsequently, the quantity and composition of the LPC feed from the bottom of the flash separator "the air-enriched oxygen", which is directly reflected on the oxygen flow rate and purity. The effect of the outlet pressure of $\mathrm{C} 3$ on product oxygen purity and flow rate is shown in Figures 3 and 4 , respectively.

The main consumption of energy in both processes is in the compressors, while other utilities energy consumption like pumps is excluded, because it is almost the same in the new and the conventional processes.

The summary of the energy consumption in the two processes is shown in Table 4. It can be seen that portion 


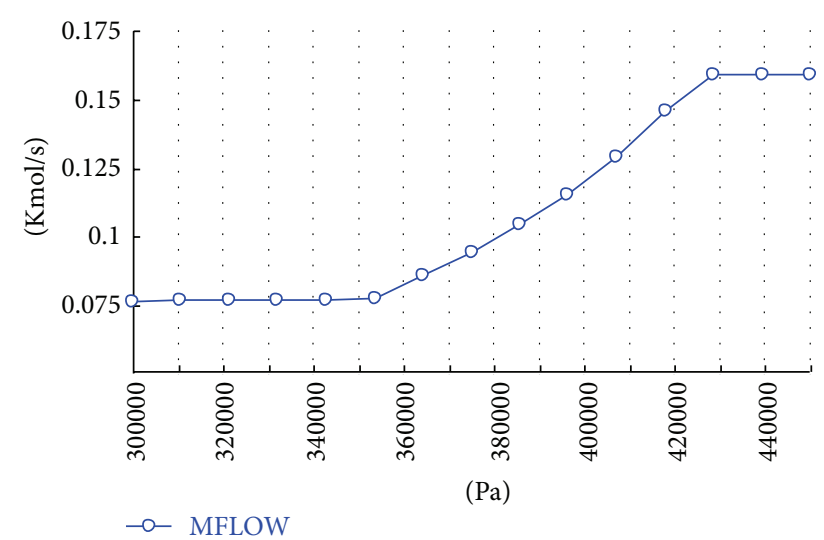

FIGURE 4: The outlet pressure of C3 versus product oxygen flow rate.

of the energy consumed in $\mathrm{C} 1$ and $\mathrm{C} 2$ of the conventional process is recovered by the turbine; however still the net energy consumption of the new process is lower due to the decrease in the compression duty.

For comparison between two processes, the specific energy consumption (SEC) may be a more meaningful measure than the net energy consumption. The SEC is defined as the net energy consumption per $\mathrm{Nm}^{3} / \mathrm{h}$ of the product, that is, $\mathrm{Nm}^{3} / \mathrm{h}$ of $\mathrm{O}_{2}$. Hence SEC for the conventional process and new process is $0.55 \mathrm{~kW} \cdot \mathrm{h} / \mathrm{Nm}^{3} \mathrm{O}_{2}$ and $0.44 \mathrm{~kW} \cdot \mathrm{h} / \mathrm{Nm}^{3}$ $\mathrm{O}_{2}$, respectively, as shown in Table 4. This is equivalent to an enhancement in SEC by about 20\%; this decrease is because the new process produces more oxygen and consumes less energy than the conventional process.

\section{Conclusion}

A new cryogenic air separation process with flash separator is developed and simulated using Aspen Plus software. In the new process the turbine of conventional double column process is replaced by a flash separator. From thermodynamic point of view the new design is better than the conventional design in two aspects: (1) the SEC is lower than that of the conventional by $20 \%$ and (2) the pure $\mathrm{O}_{2}$ produced is increased by $14.3 \%$ and pure $\mathrm{N}_{2}$ is increased by $5.4 \%$. On the other hand flash separator is more reliable than the turbine as it contains no moving parts.

\section{References}

[1] F. G. Kerry, Industrial Gas Handbook: Gas Separation and Purification, CRC \& Taylor \& Francis, New York, NY, USA, 2006.

[2] H. Cheung, "Moderate-pressure cryogenic air separation process," Gas Separation and Purification, vol. 5, no. 1, pp. 25-28, 1991.

[3] R. Agrawal, D. W. Woodward, and T. F. Yee, "Argon production from air distillation: use of a heat pump in a ternary distillation with a side rectifier," Gas Separation and Purification, vol. 8, no. 1, pp. 37-43, 1994.
[4] R. L. Cornelissen and G. G. Hirs, "Exergy analysis of cryogenic air separation," Energy Conversion and Management, vol. 39, no. 16-18, pp. 1821-1826, 1998.

[5] Y. Kansha, A. Kishimoto, T. Nakagawa, and A. Tsutsumi, "A novel cryogenic air separation process based on self-heat recuperation," Separation and Purification Technology, vol. 77, no. 3, pp. 389-396, 2011.

[6] Aspen Technology, Aspen Plus User Guide, Aspen Technology, Cambridge, Mass, USA, 2000. 

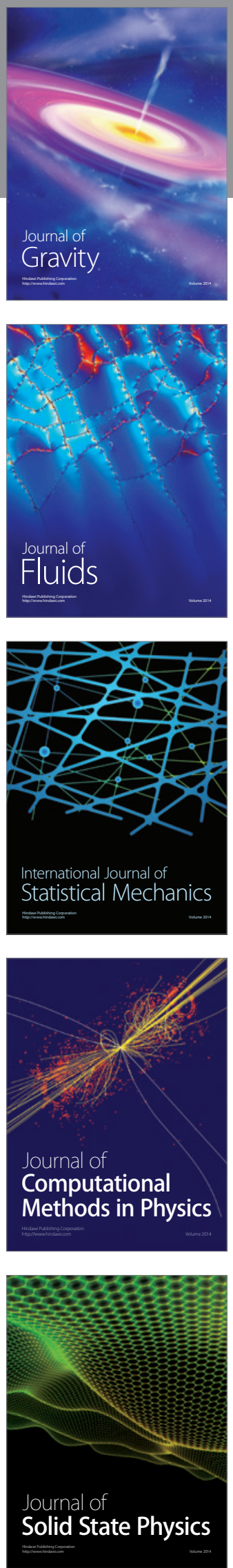

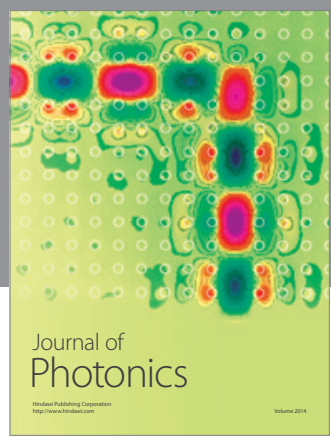

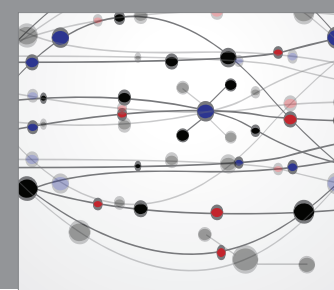

The Scientific World Journal

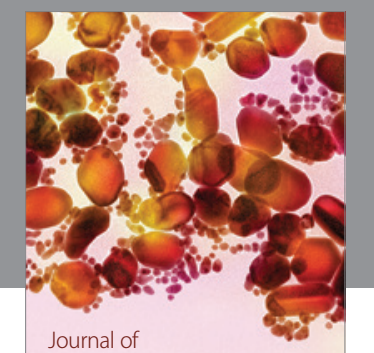

Soft Matter
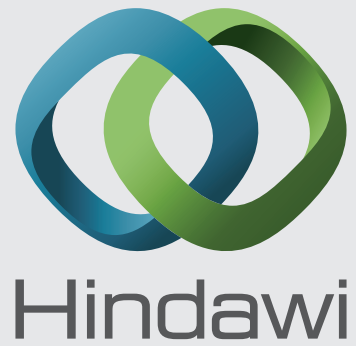

Submit your manuscripts at

http://www.hindawi.com
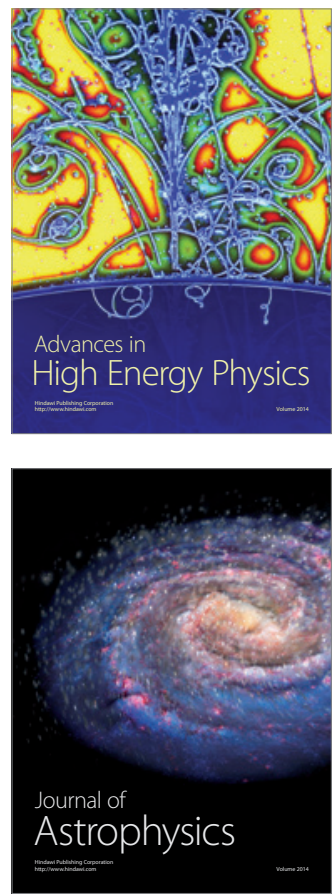
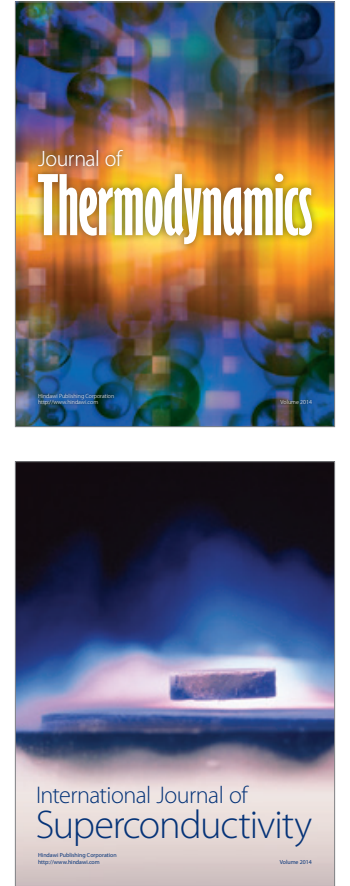
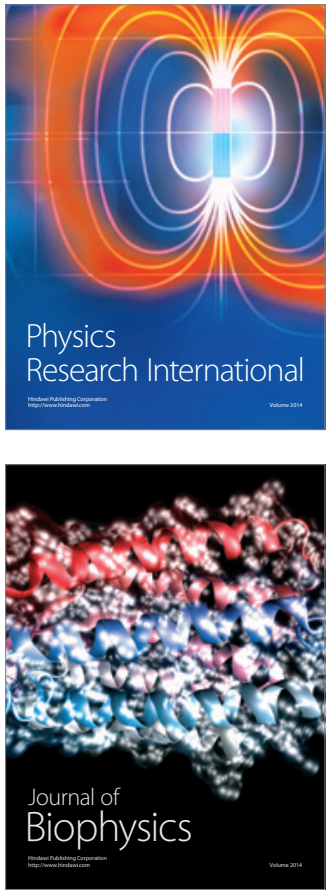
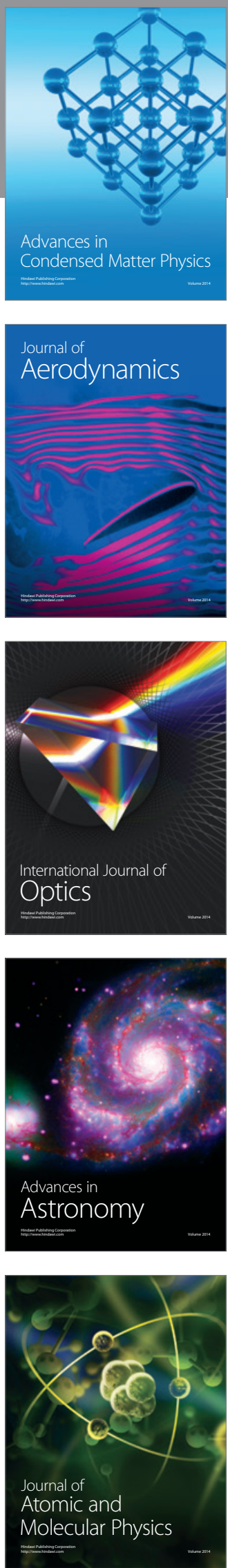